\title{
Comparison of cone-beam computed tomography with intraoral photostimulable phosphor imaging plate for diagnosis of endodontic complications: a simulation study
}

D’Addazio, P S S ; Carvalho, A C P ; Campos, C N ; Devito, K L ; Özcan, M

DOI: https://doi.org/10.1016/j.oooo.2013.02.025

Posted at the Zurich Open Repository and Archive, University of Zurich ZORA URL: https://doi.org/10.5167/uzh-100717

Journal Article

Accepted Version

Originally published at:

D’Addazio, P S S; Carvalho, A C P; Campos, C N; Devito, K L; Özcan, M (2014). Comparison of cone-beam computed tomography with intraoral photostimulable phosphor imaging plate for diagnosis of endodontic complications: a simulation study. Oral Surgery, Oral Medicine, Oral Pathology and Oral Radiology, 117(1):122-123. DOI: https://doi.org/10.1016/j.oooo.2013.02.025 


\section{Letter to the editor}

\section{D'Addazio PSS ${ }^{1}$, Carvalho ACP ${ }^{1}$, Campos $\mathrm{CN}^{2}$, Devito $\mathrm{KL}^{2}$, Özcan $\mathrm{M}^{3}$.}

${ }^{1}$ Department of Radiology, Medical School, Rio de Janeiro Federal University, Rio de Janeiro, Brazil; ${ }^{2}$ Department of Dental Clinic, Dental School, Juiz de Fora Federal University, Bairro Martelos S/N, Juiz de Fora, Brazil; ${ }^{3}$ University of Zurich, Dental Materials Unit, Center for Dental and Oral Medicine, Clinic for Fixed and Removable Prosthodontics and Dental Materials Science, Zurich, Switzerland.

\section{Dear Editor,}

With great interest we read the article by Eskandarloo et al. (2012), entitled "Comparison of cone-beam computed tomography with intraoral photostimulable phosphor imaging plate for diagnosis of endodontic complications: a simulation study" in Oral Surg Oral Med Oral Pathol Oral Radiol. This study employed a methodology very similar to a study performed by our group (D'Addazio et al., 2011). We congratulate the authors for their work but we would also like to discussion the topic with some of our observations.

Initially, we would like to emphasize that the use of simulated lesions in vitro, in a controlled study, as performed in our study (D'Addazio et al., 2011) and the study in question (Eskandarloo et al., 2012) included smaller sample size for each lesion. Certainly, sample size directly influences the reliability of the results. However, analysis of large number of images of similar lesions may lead to misinterpretation, also influencing the reliability of the results. If the examiner has not been informed about the type of injury, or whether a complication was present, a small sample size, can have a significance on the diagnosis. Moreover, in the "Material and Methods" it was described that the images obtained were cut with the CBCT apparatus and they were predefined for the analysis of observers. In fact, one of the great advantages of multiplanar images, such as CT images, is the possibility of sequential viewing of different cuts in different planes. Information from different planes would be more interesting than to manipulate images on appropriate software for each system, seeking for the injury or the complication visible in different cuts and planes. 
Concerning the acquisition of images assigned for the tomograph NewTom, the authors stated that they used a small FOV of $15.2 \mathrm{~cm}$, which is actually a large FOV. Also, in the images obtained by 3D-CT scanner Promax, the FOV used was not named. At present, it is known that the size of the FOV has a significant influence on radiation dose and image quality (Loubele et al. ${ }^{2}, 2009$ ). Thus, it is very important to correctly identify the FOV in such studies. Similarly, obtained radiographs and CT images from the jaws (Figure 3), are impossible to review for the readers as they are completely distirted. Radiographs and CT slices are shown distorted.

In the discussion concerning the data obtained from the analysis of external resorption, the authors noted that the results corroborate findings of previous in vitro studies, highlighting the limitations of obtaining, simulated lesions, similar to lesions in vivo. However, in an in vivo study, published by Patel et $\mathrm{al}^{3}$ (2009), highly satisfactory results were reported in detecting lesions of resorptions, validating the use of CBCT as the gold standard for the diagnosis of external and internal resorptions. It is also important to note that the analysis of images obtained in invitro studies excludes the information attained from the history of the patient and the clinical examination. Also, observers do not see the presence of bone lyses adjacent to certain dental injuries, which may be important in directing the demand of further information for the particular lesion.

In conclusion, despite the modifications made in this study with a larger sample size and involving more observers, the results were similar to those found in our previous study (D'Addazio et al. ${ }^{1}$, 2011). We agree with the authors that CBCT should be used cautiously that is to say only in cases where additional information is needed for digital or non-digital conventional radiography.

\section{References:}

1- D'Addazio PSS, Campos CN, Özcan M, Teixeira HGC, Passoni RM, Carvalho ACP. A comparative study between cone-beam computed tomography and periapical radiographs in the diagnosis of simulated endodontic complications. International Endodontic Journal, 44, 218-24, 2011. 
2- $\quad$ Loubele M, Jacobs R, Maes F, Denis K, White S, Condyzer W, Lambrichts I, van Steenbergue D, Suetens $P$. Image quality vs radiation dose of four cone beam computed tomography scanners. Dentomaxillofacial Radiology, 37, 309-18, 2008.

3- Patel S, Dawood A, Wilson R, Horner K, Mannocci F. The detection and management of root resorption lesions using intraoral radiography and cone beam computed tomography - an in vivo investigation. International Endodontic Journal 42, 831-8, 2009. 